\title{
Focal Segmental Glomerulosclerosis Perihilar Variant
}

National Cancer Institute

\section{Source}

National Cancer Institute. Focal Segmental Glomerulosclerosis Perihilar Variant. NCI

Thesaurus. Code C123053.

A variant of FSGS characterized by scarring of the glomerulus where at least $50 \%$ of the scars are adjacent to the hilum and must have hyalinosis; this excludes cellular, tip and collapsing FSGS. (D'Agati VD, et al. "Pathologic Classification of Focal Segmental Glomerulosclerosis: A Working Proposal." Am J Kidney Dis 43.2 (2004): 368-82.) 